\title{
AUMC Dosing to Last Concentration Normalized by Body Mass Index
}

National Cancer Institute

\section{Source}

National Cancer Institute. AUMC Dosing to Last Concentration Normalized by Body

Mass Index. NCI Thesaurus. Code C92326.

The area under the moment curve (AUMC) from the time of dosing to the last measurable concentration divided by the body mass index. 